\title{
Mirando más allá de lo técnico: la importancia del factor político en el desarrollo de las políticas públicas en el Perú 2013-2016
}

\section{The importance of the political factor in the development of public policies in Peru 2013-2016}

\section{Alexander Benites Alvarado (*) Pontificia Universidad Católica del Perú ORCID: 0000-0001-9675-1674}

\section{Frank Hurtado Paz (**)}

Pontificia Universidad Católica del Perú

ORCID: 0000-0002-6745-1266

Fecha de recepción: 8 de agosto

Fecha de aceptación: 10 de noviembre

ISSN en línea: $2415-2498$

Benites Alvarado, A., \& Hurtado Paz, F. (2018) « Mirando más allá de lo técnico: la importancia del factor político en el desarrollo de las políticas públicas en el Perú 20132016». Politai: Revista de Ciencia Política, Año 9, segundo semestre, № 17: pp. 40-89.

DOI: https://doi.org/10.18800/politai.201802.002

*Estudiante de octavo ciclo de la especialidad de Ciencia Política y Gobierno de la Pontificia Universidad Católica del Perú. Investigador del Laboratorio de Políticas Públicas de la Escuela de Gobierno y Políticas Públicas de la misma casa de estudios. a.benites@pucp.pe.

**Egresado de la carrera de Ciencia Política y Gobierno por la Pontificia Universidad Católica del Perú. Miembro del Grupo de Investigación en Políticas Públicas y Gestión Pública, e investigador del Observatorio de Políticas Públicas para la Ciudad de la Escuela de Gobierno y Políticas Públicas de la misma universidad. Se ha desempeñado como asistente de docencia y asistente de investigación en temas de políticas públicas y gestión pública.f.hurtado@pucp.pe 


\section{Sumilla}

El desarrollo de las políticas públicas, entendidas como decisiones y actividades orientadas a la resolución de problemas públicos, requiere de una gran cantidad de habilidades y saberes por parte de los tomadores de decisiones y también por parte de los directivos públicos. En esa línea, existe, actualmente, una amplia literatura que explica la importancia de que los tomadores de decisiones cuenten con habilidades técnicas y sean capaces de generar evidencia. Estas son características que deben acompañar a la política pública a lo largo de todo su proceso. Desde esta perspectiva, sin embargo, se pierde de vista el rol que cumple el factor político en el desarrollo de las políticas públicas y su importancia en dicho proceso. El presente artículo parte de la premisa de que el factor político juega, también, un papel determinante en las actividades que desarrollan los directivos públicos. En ese sentido, y dada la poca delimitación de este concepto, nuestra investigación propone su entendimiento y análisis a partir de 1) la coordinación y 2) el relacionamiento con el entorno político por parte de los tomadores de decisiones en el desarrollo de políticas públicas. Para ello, se tendrá de unidad de análisis a las políticas premiadas en el concurso de Buenas Prácticas de Gestión de Gerentes Públicos, otorgadas por la Autoridad Nacional del Servicio Civil (SERVIR), durante los años 20132016, con el objetivo de evidenciar la relevancia del factor político en el desarrollo de las mismas.

Palabras clave: Políticas Públicas, Coordinación, Entorno Político, Tomadores de decisión. 


\section{Abstract}

The development of public policies, defined as decisions and activities orientated to the solution of public problems requires a great number of skills and knowledge by the decision-makers and public managers. In that sense, there is an extensive literature that explains the importance of the technical skills and the ability to produce evidence of these actors. These two qualities should accompany the policy in its entire process. Nevertheless, from this perspective, we can easily lose sight of the role played by the political factor and its impact on the activities and strategies deployed by public managers. This article is based on the idea that the political factor plays a determinant role in the activities of public managers. For this reason, and due to the little delimitation of the concept, this investigation proposes to understand and analyze the political factor as 1) the coordination and 2) relationship with the political environment by public managers in the development of public policies. To do this, our analysis units are the public policies rewarded in $E l$ Concurso de Buenas Prácticas organized by La Autoridad Nacional del Servicio Civil (SERVIR), between 2013 and 2016, with the goal of proving the relevance of the political factor in the development of these practices.

Keywords: Public Policy, Coordination, Political Environment, Decisionmakers. 


\section{Introducción}

El estudio de las políticas públicas ha significado, por lo general, el análisis de procesos de decisiones en los que intervienen una gran cantidad de actores con miras a resolver problemas públicos. Este tipo de investigaciones se han centrado en la búsqueda de herramientas para poder enfrentarse a cualquier decisión pública y tratar de explicar cómo es que determinados problemas pasan a ser considerados como públicos, cómo y por qué se eligen determinadas estrategias para la solución de estos problemas, por qué la implementación de algunos programas tiene éxito y por qué otros fracasan, entre otros (Navarro, 2008).

Dentro de este contexto, y con la aparición de problemas cada vez más complejos, es que los gobiernos comienzan un proceso de modernización, con miras a cumplir la mayor cantidad de objetivos, haciendo uso de la menor cantidad de recursos. Es en este momento en el que se le da una mayor relevancia la figura del directivo público técnico dentro de las políticas públicas, con el objetivo de darle viabilidad y sustento técnico a las iniciativas de los actores políticos.

Algunos autores como Christopher Pollit, Geert Bouchaert (2000) y Carlos Gómez (2011) sugieren que durante este proceso de modernización de los gobiernos (así como de sus administraciones públicas) se tomaron varios elementos de la administración privada adoptando sus principios organizacionales. Este hecho dio lugar a lo que posteriormente se conoció como la Nueva Gestión Pública (NGP), la cual buscó incluir principios de eficiencia y efectividad dentro de las ya existentes burocracias estatales.

Sin embargo, creemos que también es importante el reconocimiento de características propias dentro del trabajo de la administración pública, las cuales no están presentes en la administración privada, al menos no de la misma manera. La generación de políticas públicas y de valor público responde a intereses demandados por la sociedad a quienes hay que rendir cuentas posteriormente. Además de ello, es importante reconocer que los procesos de decisiones atraviesan dinámicas complejas, debido a la naturaleza pública y política de los gobiernos, los cuales generan lo que hemos reconocido en la presente investigación como el factor político de las políticas públicas. 
Este factor político puede manifestarse de diversas maneras dentro del desarrollo de las políticas públicas: mediante procesos en los que presenta una disputa por el poder de decisión, el liderazgo o por concertar diversas visiones de la realidad. Para efectos del presente estudio, hemos decidido seleccionar -a manera de una nueva propuesta de estudio- dos elementos relevantes dentro del factor político: la coordinación en políticas públicas y el relacionamiento con el entorno político. Estos no son los únicos elementos que forman parte de dicho concepto; sin embargo, nos permitirán generar un acercamiento al mismo y al papel que ocupa dentro del desarrollo de las políticas públicas.

Del mismo modo, la presente investigación buscará dar algunas luces sobre la relevancia de esta variable dentro de las políticas públicas en el Perú. Para ello, nos proponemos realizar un análisis de las iniciativas ganadoras del concurso de Buenas Prácticas de gestión presentadas por Gerentes Públicos la cual está a cargo de la Autoridad Nacional del Servicio Civil (SERVIR) entre los años 2013 y 2016. Mediante este análisis, buscaremos medir la presencia de la coordinación de políticas públicas y del relacionamiento con el entorno político dentro de estas prácticas ganadoras del concurso.

Este documento está organizado de la siguiente manera. En primer lugar, se realizará una breve revisión sobre lo discutido en la literatura acerca de los conceptos de política pública y directivo público. En segundo lugar, se esbozará una aproximación conceptual sobre la idea de "lo político" en el desarrollo de políticas públicas; detallaremos con mayor profundidad los conceptos de coordinación intergubernamental y relacionamiento con el entorno; así como explicaremos cuál es el rol que cumple el directivo público en dicho marco. En tercer lugar, se explicará qué es el concurso de Buenas Prácticas de gestión de la Autoridad Nacional del Servicio Civil (SERVIR) y se presentarán nuestros resultados sobre la presencia del factor político para el efectivo desarrollo de tales prácticas exitosas de gestión. Finalmente, se presentarán las conclusiones de esta investigación. 


\section{Las Políticas Públicas y los Directivos Públicos}

El concepto de Política Pública aparece en la década de 1970 con el estudio de su traducción literal, Public Policy. Este término pretende estudiar a "Las interacciones, alianzas y conflictos; en un marco institucional específico; entre los diferentes actores público, para públicos y privados; para resolver un problema colectivo que requiere de una acción concertada" (Subirats, Knoepfel, Larrue \& Varone, 2008, p.35).

Uno de los primeros conceptos que se propone sobre las políticas públicas es el de Thomas Dye (1972) quien las define como "Lo que los gobiernos deciden hacer o no hacer". Posteriormente, Vincent Lemieux (1995), en un intento de complementar este concepto, propone que las políticas públicas "Están conformadas por actividades orientadas hacia la solución de problemas públicos, en la que intervienen actores políticos con interacciones estructuradas que evolucionan a lo largo del tiempo" (1995, p.7).

Bajo estas definiciones, podemos afirmar que la conceptualización de las políticas públicas debe de tener en cuenta los siguientes términos: decisiones, múltiples actores, gobierno y solución de problemas. Ante esto, Joan Subirats y otros autores (2008), en un intento por integrar la literatura existente hasta el momento, definen a las políticas públicas como:

Una serie de decisiones o de acciones, intencionalmente coherentes, tomadas por diferentes actores, públicos y a veces no públicos - cuyos recursos, nexos institucionales e intereses varían- a fin de resolver de manera puntual un problema políticamente definido como colectivo. Este conjunto de decisiones y acciones da lugar a actos formales, con un grado de obligatoriedad variable, tendentes a modificar la conducta de grupos sociales que, se supone, originaron el problema colectivo a resolver (grupos objetivo), en el interés de grupos sociales que padecen los efectos negativos del problema en cuestión (beneficiarios finales) (Subirats Knoepfel, Larrue \& Varone, 2008, p.36).

Bajo esta definición, es importante resaltar que las decisiones públicas se encuentran en constante influencia de los otros elementos que hemos identificado en la conceptualización de las políticas públicas. Es decir, las decisiones tomadas (y por tomar) se ven influenciadas por múltiples actores alrededor, por el gobierno de turno y por las perspectivas alrededor de los problemas por solucionar. Sobre esto, Isabel Maggiolo y Javier Perozo 
(2007) explican que "La política pública se relaciona con una variedad de circunstancias, personas, grupos, y organizaciones, de los cuales depende su formulación y puesta en práctica" (p.377). Todos estos factores determinan un contexto complejo y heterogéneo en el cual también interviene el régimen político de turno.

Los gobiernos tienen que lidiar en todo momento con este contexto complejo de decisión, el cual se convierte en uno de los principales retos de la administración pública. Esta tiene como función principal aportar seguridad institucional y jurídica a la sociedad para lograr su desarrollo (Ramió, 2014, p.1), mientras que la administración privada se concentra, la mayoría de veces, en la generación de mayores ganancias económicas. Adicional a ello, es importante resaltar que la administración pública tiene como ingresos a recursos públicos; por lo que está sujeta a mayores controles y a la rendición de cuentas frente a la población.

Sin embargo, en las últimas décadas, estas dos administraciones se han acercado y han compatibilizado múltiples elementos. La administración pública ha tomado elementos de la administración del sector privadoempresarial con el objetivo de conseguir mayor eficiencia y efectividad en la consecución de los objetivos:

La evolución del estado moderno hacia un estado social, prestador de servicios y del bienestar origina la crisis del modelo burocrático. Cuando los gobiernos asumieron como uno de sus cometidos la directa prestación de servicios públicos aumentó la dimensión "empresarial" de su actuación, variando su criterio de éxito desde el exclusivo cumplimiento de la legalidad a la eficacia por la satisfacción de las necesidades que encarnaban dichos servicios (Gorriti, 2010, p.3).

Es entonces cuando surge lo que algunos autores van a definir posteriormente como la Nueva Gestión Pública (Pollit \& Bouchaert, 2000; Gómez, 2011).

Este aumento de servicios prestados por parte del Estado, sumado a la aparición de problemas públicos cada vez más complejos, llevó a la necesidad de una profesionalización en la generación y desarrollo de las políticas públicas. Es en este momento cuando surge la figura del directivo público. Francisco Longo (1999 \& 2005) explica que fue el afán de eficiencia lo que provocó la necesidad de contar con profesionales, los cuales puedan 
gestionar los servicios con la consigna de lograr el máximo valor con la menor cantidad de dinero posible.

Es así que nace la idea del directivo público como un actor determinante para el accionar de las organizaciones del Estado, en la medida que funciona como una especie de nexo, que permite plasmar y poner en práctica las decisiones tomadas en los niveles más altos de las instituciones gubernamentales. Cantero, por ejemplo, señala que los directivos públicos son aquellos profesionales con capacidad de liderazgo que poseen la formación y habilidades para hacer que funcione el engranaje administrativo, bajo la dirección del gobierno de turno, y cuya gestión se somete a criterios de eficacia, eficiencia, responsabilidad y control de resultados (Cantero 2009 en Gorriti 2010). Siguiendo estas ideas, Gorriti (2010) también propone al directivo público como el nexo entre las decisiones y la puesta en práctica de la política pública. El autor define a este actor como el "Empleado que hace factible la estrategia política mediante su matización técnica y legal, la gestión de proyectos, la dirección de personas y la gestión de recursos económicos y materiales que han sido puestos bajo su responsabilidad, en orden de conseguir un servicio público eficaz" (p.21).

Para objetivos prácticos de esta investigación, una definición acertada sobre quiénes son los directivos públicos es la detallada en la Carta Iberoamericana de la Función Pública en la cual se señala que "Los directivos públicos son aquel segmento de cargos de dirección inmediatamente subordinado al nivel político de los gobiernos, cuya función es dirigir, bajo la orientación estratégica y el control de aquel, las estructuras y procesos mediante los cuales se implementan las políticas públicas y se producen y proveen los servicios públicos" (2003).

En suma, los directivos públicos son el conjunto de actores que siguen los lineamientos establecidos en el plano político de la toma de decisiones. Se encargan de dirigir equipos, adecuar procesos y generar estrategias. Todo ello enmarcado en criterios de eficiencia y eficacia para la generación de valor. Sin embargo, además de interactuar con los espacios más altos de dirección y poner en práctica las decisiones tomadas, los directivos públicos también se encargan de intermediar los intereses sociales organizados y reconocidos socialmente (Villoria, 2009). En ese sentido, la tarea que se les encarga es compleja. Además de ser el nexo que permite poner en práctica las 
decisiones, se ocupan de ser los intermediarios frente a los intereses sociales, desenvolviéndose en una arena donde cohabitan muchos grupos que manifiestan sus intereses e interactúan entre sí. Con mayor o menor nivel de organización, estos grupos se encuentran tanto dentro como fuera de la organización, y pueden presentarse como obstáculos para el alcance de los objetivos planteados. De allí que dependa del directivo y de sus capacidades para transformar estos grupos en oportunidades, al hacer uso de las competencias necesarias y las estrategias adecuadas al momento de liderar la organización (Rogers \& Guzmán, 2015).

Sin embargo, la arena donde se desarrolla el directivo no solo se encuentra llena de intereses en conflicto, sino que también cambia constantemente. Esto vuelve su labor aún más compleja. Los intereses ciudadanos, los métodos para llevar a cabo ciertas actividades, los procedimientos y los problemas a los que se enfrenta la organización nunca son estáticos. Por ello, como señala Moore "No basta pues con que los directivos solo se preocupen de las rutinas organizativas, ni tampoco que traten de ser más eficientes en las tareas rutinarias. También es necesario que la organización esté preparada para adaptarse a nuevas demandas, y que sea innovadora y esté abierta a la experimentación. Este es el objeto de trabajo del directivo en el sector público" (1998). El directivo público no solo debe hacer frente a las dificultades propias de los procedimientos organizativos y los intereses en conflicto, sino que, además, se enfrenta a cambios en el entorno en el cual se desarrolla la organización a la que pertenece.

La literatura ha abordado múltiples formas de clasificar a los directivos públicos. Esto debido al hecho de que desempeñan diversas funciones y ocupan varios roles. Por ejemplo, Gorriti señala que es adecuado clasificar a los directivos según las funciones que desempeñan en relación a sus superiores, sus quehaceres y sus subordinados (2010). En ese sentido, el siguiente cuadro muestra la clasificación establecida por el autor: 


\begin{tabular}{|c|c|}
\hline Relación del directivo: & Actividades: \\
\hline $\begin{array}{l}\text { Funciones del directivo } \\
\text { público en relación con } \\
\text { sus superiores políticos }\end{array}$ & $\begin{array}{l}\text { - Operativización de la estrategia política } \\
\text { mediante metas y proyectos. } \\
\text { - Análisis de la viabilidad legal y } \\
\text { presupuestaria. } \\
\text { - Informar sobre los cambios en las } \\
\text { necesidades del servicio y proponer } \\
\text { mejoras a la estrategia política. } \\
\text { - Mediación entre políticos y técnicos. }\end{array}$ \\
\hline $\begin{array}{l}\text { Funciones del directivo en } \\
\text { relación a la tarea }\end{array}$ & 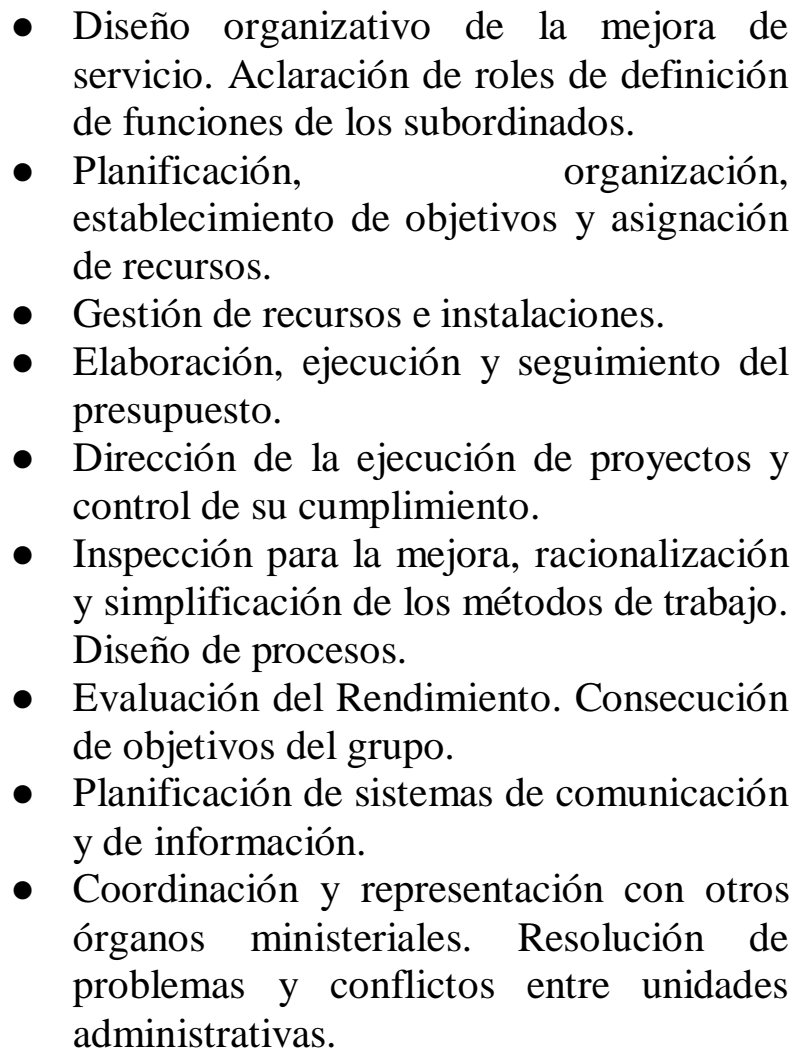 \\
\hline
\end{tabular}


Funciones del directivo en relación con sus subordinados
- Establecimiento de cauces formales y personales de comunicación con sus subordinados.

- Establecer una amplia red de relaciones en el ámbito de su competencia.

- Motivación y conformación de equipos. Gestión de la formación de sus subordinados.

- Representación, identidad y defensa del equipo y sus miembros.

- Evaluación del desempeño individual y gestión del reconocimiento.

- Gestión de conflictos entre personas.

Cuadro 1. Roles de los Directivos Públicos según Gorriti, 2010, p.12

Se observa que las actividades desempeñadas por los directivos públicos varían según sus funciones, así como la relación entre estas y un tipo de actor o quehacer específico.

Otra forma de clasificar a los directivos públicos puede ser según los roles que desempeñan en función de las exigencias organizativas. En esa línea, Losada (1999) identifica los siguientes roles de los directivos en la función pública:

- Rol de resolución de conflictos: conjunto de pautas o comportamientos orientados a enfrentar crisis o conflictos normalmente imprevistos en procura de su solución.

- Rol de emprendedor e innovador: conjunto de comportamientos orientados a introducir cambios controlados, con actitud proactiva y estando atento al entorno que lo rodea.

- Rol de negociador: el directivo actúa como cabeza visible de la organización aportando credibilidad a los actos, representándola exteriormente y comprometiendo recursos durante la negociación en su calidad de asignador de los mismos, mediante el uso de estrategias de negociación formales e informales. 
- Rol de asignador de recursos: es el conjunto de comportamientos orientados a distribuir entre diversas alternativas los recursos disponibles (dinero, material, personal, tiempo) o a protegerlos ante posibles cambios de asignación. El directivo debe ser capaz de establecer prioridades.

- Rol de monitor: es el conjunto de comportamientos orientados a buscar o recibir información relevante para el funcionamiento de la organización.

- Rol de difusor: el directivo debe ser capaz de transmitir al interior de la organización la información que es relevante para su correcto funcionamiento.

- Rol de portavoz: es el conjunto de comportamientos orientados a transmitir la información fuera de la unidad dependiente formalmente del directivo, trátese del superior jerárquico, de otras unidades de la organización, organismos relacionados, proveedores, usuarios u opinión pública.

- Rol de control: consiste en que el directivo sea capaz de desarrollar una serie de pautas orientadas a lograr el comportamiento deseado de las personas en la organización o alrededor de ella.

- Rol de representación: el nombramiento formal de un directivo público lo convierte en un símbolo representativo de su unidad u organización en actos públicos, bienvenidas $\mathrm{u}$ otros eventos formales.

Estos dos ejemplos muestran la gran variedad de funciones que los directivos desempeñan, los roles que ocupan y las tareas que se les encarga. Sin embargo, todas las clasificaciones encuentran similitudes, en la medida que se orientan a la identificación de características que les permitan a estos actores manejar de forma satisfactoria los procedimientos internos de la organización a la que pertenecen, gestionar los intereses en conflicto al 
interior y al exterior de las instituciones que representan, y, por último, crear valor público.

En el caso peruano, el Estado está compuesto por una gran cantidad de organizaciones, las cuales poseen características diferentes y desempeñan distintas funciones. Todas ellas se encuentran distribuidas en los tres niveles de gobierno: el nacional, el regional y el local. En el caso del Gobierno Nacional, este se encuentra organizado en tres poderes (ejecutivo, legislativo y judicial) y en organismos constitucionalmente autónomos; los cuales, mediante su funcionamiento en conjunto, estructuran la acción gubernamental (SERVIR, 2016a, p.17). En ese sentido, la administración pública se caracteriza por poseer a dos actores protagónicos en la acción estatal: los funcionarios públicos y los directivos públicos, quienes se encuentran acompañados por los servidores públicos técnicos encargados de la administración operativa y la denominada "Burocracia de la calle" (Alza, 2018, p. 9).

El artículo $\mathrm{N}^{\mathrm{o}} 51$ de la Ley de Servicio Civil define a los funcionarios públicos como actores que ejercen atribuciones políticas administrativas y normativas; es decir, diseñan y aprueban políticas y normas de carácter general en su ámbito de competencia, así como dirigen la gestión interna de sus organizaciones. Por su parte, el artículo $\mathrm{N}^{\mathrm{o}} 52$ de la misma ley los agrupa en a) aquellos funcionarios elegidos por elección popular, directa y universal; b) funcionarios designados o de remoción regulada; y c) los de libre designación y remoción (Ley 30057, 2013). Sin embargo, aunque formalmente, los funcionarios públicos vendrían a ser autoridades políticas, ello no implica que sean los únicos que deban desarrollar visión y competencia política (Alza, 2018, p.9). El desarrollo de una política pública se encuentra, a lo largo de todo su proceso, inmerso en un entorno complejo y cambiante, en el cual intervienen actores con intereses diversos que muchas veces entran en conflicto, tanto dentro como fuera del sistema político. Por ello, los actores encargados de llevarlas a cabo deben ser conscientes de ello y desarrollar estrategias para vencer tales obstáculos. En este contexto, los directivos públicos ocupan un rol fundamental.

El artículo ํo3 de la misma ley define a los directivos públicos como el conjunto de servidores civiles que desempeñan funciones relativas a la organización, dirección o toma de decisiones de un órgano, unidad orgánica, 
proyecto especial o programa Ley 30057, 2013). Por ello, y como ya fue señalado, debido a la amplitud de sus funciones y a la complejidad del entorno en el cual se desenvuelven los directivos públicos, SERVIR (2016a) agrupa a este conjunto de actores en tres grandes roles desempeñados:

- Dirección político-estratégica: son el conjunto de puestos que se encargan de liderar procesos de negociación y coordinación intergubernamental, así como gestionar la formulación y desarrollo de políticas públicas.

- Dirección estratégica: abarca el conjunto de puestos que se caracterizan por dirigir el diseño y evaluación de políticas públicas. Asimismo, se encargan de liderar el desarrollo de los objetivos estratégicos e institucionales.

- Dirección operativo-estratégica: abarca un conjunto de puesto, en el cual prima la capacidad técnica para el logro de resultados planteados.

A modo de síntesis, queda claro que los directivos públicos son un conglomerado de actores, al interior de las organizaciones públicas, que ocupan un rol de suma importancia para el desarrollo de las actividades gubernamentales y para el desarrollo de las políticas públicas. Se constituyen como el nexo entre las decisiones tomadas por los actores políticos en el más alto nivel de autoridad y la puesta en práctica de dichas decisiones públicas. Las distintas formas de clasificación que la literatura ha propuesto sobre los directivos brindan luces sobres las diversas funciones que realiza y competencias que debe poseer en el ejercicio de su labor directiva. En ese sentido, todo ello se desarrolla en el marco de actores estatales y no-estatales, con intereses en conflicto y en entornos cambiantes. Lo que obliga a este conjunto de actores a desarrollar capacidades de coordinación y relacionamiento con el entorno político. Ambos conceptos serán desarrollados a mayor profundidad en las siguientes secciones.

\section{El Factor Político dentro de las Políticas Públicas}


Una amplia literatura en ciencia política y administración pública se ha enfocado en el estudio de la Nueva Gestión Pública y su implementación en el sector público (Hood, 1991; Pollit \& Bouckaert, 2000; Barzelay, 2001). Debido a sus conocidas falencias, procedimientos engorrosos, gestión inefectiva y corrupción en diversos ámbitos, varios trabajos mostraron una preocupación por conocer los factores que puedan ayudar a mejorar ese deficiente funcionamiento. Así, la idea fue virar hacia un modelo gerencial de administración con la finalidad de extrapolar prácticas del sector privado al sector público. El paradigma gerencial tiene sus fuentes en los procedimientos observados en el sector privado: el cual, apuesta por transformar al Estado en una organización con mayor flexibilidad y autonomía gerencial, que genere respuestas adecuadas frente a problemas públicos; la construcción de una red más democrática de relaciones entre los ciudadanos consumidores, por un lado, y la prestación de servicios públicos, por el otro. Así como la adopción de un modelo contractual que opera bajo la lógica de la eficiencia y la eficacia (CLAD, 1999; Hood, 1991; Losada, 1998).

Más allá de que algunos autores señalan que la adopción de este modelo en países con diseños institucionales distintos puede ser problemática: transforman las supuestas bondades del modelo gerencial en trabas que impiden la eficiencia y la generación de valor público (Ramió, 2001). E incluso otros han declarado la "muerte" de este paradigma de gestión (Guerrero, 2009). Una de sus consecuencias más importantes ha sido la separación entre la política y la gestión en el funcionamiento del Estado. Este distanciamiento tiene varias explicaciones. Peters señala que una gestión separada de los espacios políticos permite a los administradores participar de procesos políticos sin la necesidad de que tengan que responder por sus acciones. Esto, sin embargo, también sucede del lado contrario: el distanciamiento entre la política y la gestión libra a los políticos de tener que tomar muchas de las difíciles decisiones de gobierno (1999).

En ese sentido, y sin desmerecer los beneficios que pueden generarse a partir de la adopción de prácticas del sector privado por parte del sector público, el distanciamiento resultante entre política y gestión -debido a la implantación del modelo gerencial de administración- resulta en cierta medida problemático: dado que la esencia misma de la acción estatal parte de una 
lógica en la cual las políticas públicas son respuestas a problemas políticamente inaceptables en la sociedad (Subirats, Knoepfel, Larrue \& Varonne, 2008). Tratar de aislar a la administración pública, restringiéndola a criterios de razonabilidad técnica, sería ignorar su naturaleza eminentemente política. Podemos decir, entonces, que el factor político sí importa (Alza, 2018). Ello en la medida que permite tener un entendimiento del Estado y su funcionamiento en toda su complejidad. En esa línea, Hernandez, Sanchez y Vargas señalan lo siguiente:

El gobierno crea valor público para la sociedad con sus políticas y servicios públicos, y por ende estas deben responder a las expectativas y deseos de los ciudadanos. Los bienes y servicios del gobierno no producen valor público si descuidan la valoración que hacen los ciudadanos tanto de los fines como de los resultados alcanzados. En ese sentido, las actividades públicas no se pueden concebir independientemente de la participación y las expectativas de los ciudadanos. Los bienes y servicios que producen las organizaciones públicas son una expresión imperfecta de los deseos de los ciudadanos expresados a través de las elecciones y demás instituciones del sistema representativo (2002, p.14).

Los autores son enfáticos al señalar que la creación de valor y las respuestas a demandas sociales por parte de las organizaciones públicas se encuentran engarzadas a la misma legitimidad del sistema democrático. Y, en consecuencia, la dirección de estas organizaciones tiene una ineludible y necesaria naturaleza política (Ramió \& Rovira, 2009).

En tal sentido, a lo largo de todo el proceso de una política pública, los directivos se enfrentan a la presión de intereses por parte de actores que se encuentran tanto dentro como fuera del sistema político. Y, para llevar adelante sus objetivos, les es necesario el desarrollo de estrategias que otorguen legitimidad a sus actividades por parte de los actores al interior de sus organizaciones; actores de organizaciones gubernamentales independientes; y actores no-estatales, tales como los medios de comunicación, la cooperación internacional y la sociedad civil. Este espacio de intereses en conflicto representa, en esta investigación, el factor político en el desarrollo de políticas públicas el cual analizaremos a partir de a) la coordinación en las políticas públicas y b) el relacionamiento con el entorno. Estos dos elementos están vinculados a las relaciones que se generan en los actores alrededor de la toma de decisiones públicas, y mediante ellos 
podemos apreciar diversas situaciones de disputa, debate, influencia, y otras formas de presión política.

Conseguir el apoyo de otros actores es una pieza importante en el desarrollo de las políticas públicas. Stein y Tommasi (2006) sostienen que es más probable que surjan mejores políticas si los múltiples actores cooperan entre sí para defender acuerdos y sostenerlos en el tiempo (p.413). Estudiar el proceso de coordinación dentro de las políticas públicas nos permite comprender la relación de actores dentro del gobierno, dicho de otra forma, nos permite comprender la forma en la que los tomadores de decisiones consiguen la cooperación de otros funcionarios públicos de otros sectores o niveles de gobierno. Por otro lado, el estudio del relacionamiento de los directivos públicos con su entorno político nos permite comprender la relación de estos con actores fuera del gobierno, es decir, la forma en la que consiguen cooperación de la sociedad civil, medios de comunicación, cooperación internacional, entre otros.

Cabe resaltar que el factor político presente dentro de las políticas públicas no es un concepto cerrado, y su estudio sigue siendo un tema pendiente dentro de las agendas de investigación en políticas públicas. Nuestra propuesta plantea el estudio del mismo, a partir de dos elementos, los cuales consideramos relevantes, más no absolutos. Es decir, el factor político también contiene otros elementos, los cuales no son desarrollados en la presente investigación y que son materia de un debate más amplio. A continuación, ambos conceptos serán descritos en mayor profundidad ${ }^{1}$.

\section{a) La Coordinación en las políticas públicas}

Como ya hemos mencionado en líneas anteriores, los problemas públicos son parte importante en la generación de políticas públicas. Estos son resueltos con intervenciones desde un determinado nivel de gobierno (nacional, regional o local) o desde algún sector específico de este (transportes, salud, educación, etc.). Sin embargo, en los últimos años, se ha consolidado la certeza de que muchos problemas sociales tienen un carácter

\footnotetext{
${ }^{1}$ Los contenidos desarrollados en la parte de coordinación de políticas públicas forman parte de una investigación más grande desarrollada por Frank Hurtado, autor del presente documento, como parte de su tesis de licenciatura.
} 
multidimensional y multicausal. "Esto quiere decir que el bienestar de los individuos, familias, comunidades y territorios no se ve afectado solo cuando hay una única carencia o necesidad básica insatisfecha (por ejemplo, de ingresos), sino que hay otras dimensiones (salud, educación, hábitat, etc.) cuya insatisfacción incide profundamente en la calidad de vida." (Repetto \& Fernández, 2012, p.37).

Es importante reconocer que las sociedades vienen enfrentándose día a día a problemas cada vez más complejos. Estos no deben ser respondidos solo de una manera o desde solo un sector del gobierno. Para enfrentar a estos problemas, es necesario que los gobiernos actúen de forma colaboradora y coordinada (Navarro, 2013, p.15), y que pongan en una misma línea el trabajo de varias instituciones, sectores o niveles al interior de todo el Estado con miras a lograr objetivos en común. Es acá donde surge el concepto de la coordinación en políticas públicas.

Roberto Martínez Nogueira (2010) define a la coordinación en políticas públicas como el "Proceso de creación o de utilización de reglas de decisión con el que dos o más actores se ocupan de un entorno de trabajo compartido" (p.20). En ese mismo sentido, Isabel Licha (2006) propone a este concepto como un proceso político y técnico orientado a lograr la coherencia y articulación para favorecer a objetivos estratégicos.

En suma, podemos decir que la coordinación en políticas públicas es el proceso mediante el cual diferentes actores, involucrados en una misma política pública, reúnen y armonizan sus esfuerzos, con miras a lograr un objetivo en común, construyendo dinámicas formales e informales de toma de decisión en un entorno de trabajo compartido. Este tiene las características de ser un proceso político y técnico al mismo tiempo; participativo y concertado; horizontal y vertical simultáneamente; así como poseer distintos alcances. (Licha \& Molina, 2006).

Decimos que la coordinación es un proceso político debido a que trabaja con una gran cantidad de actores y busca generar convergencias en ellos. Para lograr esto es necesario recurrir a procesos de negociación y hacer que los distintos actores puedan ponerse de acuerdo sobre el desarrollo de una determinada iniciativa. La coordinación implica "Enfrentar las contradicciones, restricciones y resistencias; además de consultar, cooperar y 
negociar con los actores gubernamentales y no gubernamentales" (Repetto \& Fernández, 2012, p.46). Decimos también que este es un proceso técnico debido a que requiere de habilidades, por parte de los funcionarios públicos, para el diagnóstico de los problemas y el planteamiento de soluciones, muchas veces creativas, que permitan lidiar con todas las dimensiones de estos problemas. Para esto es necesario contar con un enfoque participativo y de concertación.

Es importante resaltar también que este puede ser un proceso horizontal y vertical. La coordinación horizontal -también llamada coordinación intersectorial- implica el trabajo en conjunto de diversos sectores o instituciones en un mismo nivel de gobierno y se produce por lo general en el gobierno central. Por otro lado, la coordinación vertical -también llamada coordinación intergubernamental- se produce entre distintos niveles de gobierno, haciendo que el gobierno central se involucre en las políticas locales junto a los gobiernos de carácter regional o local. Ambas formas de coordinación son complementarias y permiten alcanzar mejores soluciones a problemas públicos.

La ausencia de coordinación puede derivar en, al menos, dos escenarios negativos: La desarticulación fragmentación y la tecnocratización despolitización (Licha \& Molina, 2006; Repetto \& Fernández, 2012). La desarticulación se produce cuando se formulan e implementan políticas de forma aislada, resultando así una especie de mosaico del cual es imposible determinar la relación entre las distintas partes. Con este escenario se pierden recursos y oportunidades para un mejor desarrollo de los servicios y soluciones a problemas públicos. Por otro lado, la tecnocratización es un escenario en el que la coordinación se vuelve únicamente operativa y pierde todo horizonte de acción para generar metas a corto y largo plazo. "Si se reduce a un asunto técnico, la coordinación pierde su función principal, es decir, su habilidad para concertar visiones y perspectivas entre actores, para que se traduzcan en un accionar público integrado." (Repetto \& Fernández, 2012, p.41).

Repetto y Fernández (2012) añaden también que la falta de coordinación reduce la eficiencia y eficacia de las organizaciones involucradas, incrementa los costos operativos, complica el uso eficiente de los fondos públicos y debilita el sentido de pertenencia al ámbito público. Sin la coordinación se 
perdería una gran cantidad de aportes especializados sobre realidades multidimensionales.

La coordinación es una herramienta que nos permite la consecución de objetivos; sin embargo, esta también puede ser vista como un elemento digno de ser objeto de estudio y con objetivos propios. Peters (1998) explica que los objetivos de la coordinación en políticas públicas son los siguientes:

- Evitar o minimizar la duplicación y superposición de políticas

- Reducir las inconsistencias de las políticas

- Asegurar las prioridades y apuntar a su cohesión y coherencia

- Atenuar el conflicto político/burocrático

- Promover una perspectiva holística, que supere la mirada sectorial y estrecha de las políticas 
Factores de Membresía

$$
\begin{aligned}
& \text { Inclusión de todos los actores interesados } \\
& \text { Incentivos para la coordinación } \\
& \text { o Valores profesionales compartidos } \\
& \text { o Búsqueda de soluciones a problemas comunes } \\
& \text { o Reducción de incertidumbre } \\
& \text { o Mandato Legal } \\
& \text { Liderazgo Efectivo }
\end{aligned}
$$

Factores de Proceso

Estructura de toma de decisiones

o Distribución equitativa de oportunidades

o Marco regulador plausible

Organización y centralización del proceso de coordinación

o Grado de formalización del acoplamiento organizacional

o Nivel de recursos comprometidos en los esfuerzos intergubernamentales

o Mecanismo de control encaminado al cumplimiento de metas colectivas

Relaciones formales e informales entre actores intergubernamentales

o Ideología compartida

o Construcción de lazos de confianza

o Establecimiento de líneas abiertas de comunicación

Factores externos

Recursos financieros

Interés político

Cuadro 2. Elementos de la Coordinación en políticas públicas según Gray (1989) en Navarro (2013)

Finalmente, y respecto a qué elementos constituyen o forman parte de la coordinación en políticas públicas, podemos decir que tenemos dos grandes propuestas. En primer lugar, Gray (1989) propone que los factores que influyen en el proceso de coordinación se dividen en tres tipos: los de membresía, los de proceso y los factores externos. Estos son explicados de forma más profunda por Alejandro Navarro (2013). Dentro de los factores de membresía, tenemos a la inclusión de todos los actores interesados, la presencia de incentivos para la coordinación y de un liderazgo efectivo. Del mismo modo dentro de los factores de proceso, tenemos a la estructura de toma de decisiones, la organización y centralización del proceso y las 
relaciones formales e informales de los actores. Finalmente, los factores externos están conformados por los recursos financieros y el interés político.

Otra propuesta de factores que forman parte de la coordinación es la planteada por Licha y Molina (2006) quienes plantean una lista de criterios básicos que forman parte de este proceso. Estos son: voluntad y cohesión política; definición de objetivos estratégicos; estructuras y mecanismos de coordinación (con funciones y objetivos claramente definidos); participación de los actores; institucionalidad legítima; capacidad de coordinación y liderazgo; espacios de diálogo y deliberación; sinergias; cultura de cooperación e incentivos; y la presencia de sistemas de información, comunicación, monitoreo y evaluación.

\section{b) EI Relacionamiento con el Entorno Político}

En las secciones anteriores hemos señalado la complejidad que posee la tarea directiva en la administración pública. Parte de dicha complejidad se encuentra en la existencia de un entorno político dentro del desarrollo de sus funciones. Este será entendido como una arena de conflicto constante entre actores de diverso tipo y con distintas posibilidades de influencia en el desarrollo de política. Todo ello es una muestra de la particularidad en el accionar de los directivos públicos como detallaremos a continuación.

Como señala Mejía, los directivos públicos podrían asemejarse a los directivos privados -incluso tienen formas similares de manejar la organización-; sin embargo, el autor señala que los primeros operan bajo situaciones muy distintas, en las cuales existen intereses al interior de la organización a la que pertenecen, en otras organizaciones independientes y en actores externos al Estado. Por consiguiente, la actuación de los directivos se encuentra sujeta a los diversos efectos que sus decisiones puedan generar en un plano social y político (2014). En ese sentido, si bien es cierto que son los mecanismos institucionales los que establecen canales específicos a seguir para la elaboración de políticas públicas, así como las competencias que tienen cada uno de los actores públicos, esto no implica que los espacios sean estáticos. A lo largo del proceso de política, interactúan actores públicos y no públicos, desplegando estrategias y posibilitando la acción colectiva (Subirats, Knoepfel, Larrue \& Varonne, 2008). Más aún, como señala Kingdon, la línea que establece la separación entre los actores públicos y no 
públicos -o actores dentro y fuera del gobierno- es bastante borrosa (2003). En palabras del autor:

Las personas pasan con facilidad desde dentro y fuera del gobierno, a veces ocupan cargos gubernamentales y otras veces son lobbistas, consultores o simplemente nombres importantes en las ciudades. Los canales de comunicación entre los que están dentro y los que están fuera del gobierno son extraordinariamente abiertos, y las ideas y la información flotan a través de estos canales en toda la red de temas de personas involucradas, algo independiente de sus posiciones formales. Finalmente, valores comunes, orientaciones y visiones del mundo son puentes, al menos en cierta medida, entre los que están dentro y los que están fuera del gobierno (p. 45).

De estos aportes teóricos, el entorno político en las políticas públicas podría plantearse como una arena de constante interacción entre actores estatales y otro conjunto de actores que -al menos en términos formales- se encuentran fuera del aparato público. Los cuales despliegan estrategias, utilizan recursos de diverso tipo y forman coaliciones a partir de la manera en la cual conciben el mundo, buscando influir a lo largo de todo el desarrollo de una política pública. Como señala Kingdon, si bien la línea que separa a estos dos grupos de actores es difusa, los que se encuentran fuera del aparato público, o sin una posición formal dentro del gobierno, puede incluir a grupos de interés, académicos, consultores, medios de comunicación, partidos políticos y la sociedad en general (2003). De aquí que, para el correcto desarrollo de una política pública, los directivos públicos deban ser conscientes del ambiente que los rodea y reconocer a los actores que se encuentran involucrados en dicho proceso.

Si bien es cierto que no existe una definición específica sobre el concepto de "entorno político", varios autores se han referido a él cuando han abordado la manera en que interactúan diferentes actores a lo largo de las fases del desarrollo de una política pública o cuando han estudiado la influencia de actores externos en el accionar de los directivos públicos. En esa línea, Stein y Tomassi llaman la atención sobre cómo ciertos actores en la sociedad, como sindicatos, la iglesia y los medios de comunicación forman parte del proceso de formulación de políticas, poniendo en debate la idea de que esta fase del proceso de desarrollo de la política se encuentra restringida a actores al interior del aparato estatal tales como el presidente o el congreso (2006). Sin embargo, estos mismos actores son capaces de influir en el proceso de 
agendación de políticas, bloqueando o promoviendo temas según la capacidad de injerencia que posean y los recursos que tengan a su disposición (Kingdon, 2003).

De forma específica, Moore señala que ciertos grupos de interés -como, por ejemplo, empresas- son capaces de influenciar la acción directiva. El autor señala que estos grupos disponen de relaciones estables con el entorno autorizador y pueden adentrarse en las organizaciones de los directivos, siendo capaces de convertirse en obstáculos o amplificadores de objetivos de los directivos, según estos se encuentren en sintonía -o no- con los suyos (1998, p.185). Sin embargo, Moore también señala que otro tipo de actores, como los medios de comunicación, también pueden ser una suerte de amplificadores de objetivos directivos, ya que "Dado que los medios a menudo determinan el contexto en el cual se toman las decisiones políticas y los ciudadanos se movilizan, muchos directivos públicos intentan implicar a la prensa a través de estrategias de prensa más o menos formalizadas" (1998, p.182). En ese sentido, los medios son capaces de poner temas en agenda (Kingdon, 2003) e influir en la opinión pública, incitando a actores públicos a apropiarse de esos temas para hacer valer sus ideas y presentare con un perfil propio frente al electorado (Subirats, Knoepfel, Larrue \& Varonne, 2008, p.139). Finalmente, las empresas y los medios de comunicación no siempre trabajan de manera separada, pueden articularse con la finalidad de tener una mayor injerencia en las decisiones directivas y las políticas públicas (Acevedo, 2017).

Además de los actores domésticos, Adam y Kriesi llaman la atención sobre la relevancia de los "entornos políticos internacionales", los cuales pueden influenciar las redes de política a nivel doméstico, mediante la distribución recursos y reapertura de temas de importancia en la agenda nacional (2007). Y, en la línea de lo planteado por los autores, Alza (2018) también brinda algunas luces sobre cómo los actores no-domésticos pueden tener un rol importante a la hora de implementar políticas públicas. En ese sentido, explica que si

La propuesta del directivo público gira en torno a la atención de las personas con discapacidad en el distrito, no sería vano prestar atención a las agencias de colaboración que estén aportando en ese tema en el Perú. En algunos casos, algunas de ellas tienen atenciones definidas y focalizadas en 
determinadas regiones, por lo que puede ser una gran oportunidad para las ciudades intermedias y poblados rurales (p.27).

Como se observa, el número y tipo de actores que entran en juego, así como su capacidad de influencia, es vasta y cambia dependiendo del contexto.

Finalmente, la sociedad civil también juega un rol importante en varias de las fases del desarrollo de una política pública. Como señala Alza, "La sociedad civil y su grado de participación en los temas políticos de la comunidad marcan también una influencia clave en el trabajo de los directivos públicos. Una sociedad civil fuerte puede convertirse en un aliado fundamental para lograr reformas y la legitimidad y aceptación de las propuestas, tanto como una tenaz oposición a las propuestas del directivo público" (2018, p.28). En esa línea, muchas veces depende de las capacidades y estrategias desplegadas por los directivos públicos transformar a la sociedad civil en un actor aliado y acorde con sus intereses. Las estrategias comunicacionales, los resultados de corto plazo y la construcción de legitimidad son fundamentales para lograr tal cometido. Así, por ejemplo, existen casos en los que la sociedad lleva a cabo un rol importante para el cumplimiento de la ley, incluso cuando el Estado es incapaz de lograrlo por sus propios medios. Amengual, en esa línea, señala que existen diferentes tipologías de enforcement, las cuales se encuentran en función del grado de influencia de diferentes sectores sociales interesados en el cumplimiento de la norma y los burócratas encargados de hacerla cumplir (2016). En suma, la participación de la sociedad en la porosa dinámica del desarrollo de políticas públicas resulta fundamental para su entendimiento.

Dicho todo lo anterior, ¿por qué sería importante para los directivos un buen relacionamiento con el entorno político? Aquí, el trabajo de Mark Moore resulta sumamente influyente. El autor responde a esta pregunta de forma muy concreta:

La gestión política es una función importante por una razón muy sencilla: para conseguir objetivos operativos, los directivos públicos a menudo necesitan la colaboración de actores que están fuera del ámbito de su autoridad directa. Generalmente, los directivos necesitan estos actores externos por una o varias de las siguientes razones: les es necesario su permiso para utilizar recursos públicos para una determinada misión, o su apoyo operativo para producir los resultados de los cuales son responsables. Dado que dichos actores se encuentran fuera del ámbito de la autoridad 
directa de directivo, este no puede simplemente ordenarles una determinada acción, sino que debe persuadirles (1998, p. 174).

Sacar adelante objetivos de política siempre involucra desenvolverse en entornos conflictivos y cambiantes, interactuando con actores que muy pocas veces se encuentran bajo el ámbito de autoridad directa de los directivos responsables. En ese sentido, desarrollar estrategias y capacidades directivas para relacionarse adecuadamente con el entorno; transformar posibles detractores en aliados; y convencer a actores externos sobre la relevancia de las decisiones a implementar, resulta de vital importancia en el accionar de las organizaciones públicas.

Moore (1998) define la gestión política como compuesta por cuatro elementos: 1) la construcción de un clima de tolerancia, apoyo activo o asistencia operativa para 2) un directivo, una política o estrategia global entre 3) aquellos agentes fuera del ámbito de autoridad directa del directivo 4) cuya autorización o cooperación es necesaria para conseguir los objetivos públicos de los cuales el directivo deberá rendir cuentas (p.173). En tal sentido, siguiendo la lógica de lo planteado por Moore y todo lo discutido por otros autores en relación a la idea de entorno político, y cómo este se encuentra muy ligado al desarrollo de políticas públicas, un buen relacionamiento con el mismo por parte de los directivos públicos resulta fundamental.

\section{c) Concurso de Buenas Prácticas de Gestión presentadas por Gerentes Públicos-SERVIR}

La Autoridad Nacional del Servicio Civil del Perú (SERVIR) premia cada año, desde el 2013, las buenas prácticas presentadas por diversos gerentes públicos. Con el objetivo de identificarlas, reconocerlas y difundirlas. Esta institución reconoce como Buena Práctica a "Una actividad o proceso que ha obtenido destacados resultados en el manejo de la organización en beneficio de la ciudadanía" (Ciudadanos al día, 2016 en SERVIR, 2018). Estas pueden ser replicadas por otras instituciones con miras a mejorar la efectividad, eficiencia y los procesos innovadores dentro de la gestión pública.

Durante sus 6 primeras ediciones, desde el 2013 al 2018, este concurso ha venido consolidándose $\mathrm{y}$ creciendo en cuanto a su difusión, llegada $\mathrm{y}$ cantidad de prácticas reconocidas. Según la página web de SERVIR, en el 
año 2013 se premiaron en seis distintas categorías de buenas prácticas; mientras que para el año 2018 ya se contó con veinte categorías diferentes. Cabe resaltar también que la cantidad de prácticas premiadas provenientes del interior del país también ha ido en aumento conforme han avanzado las ediciones.

Las Bases del Concurso de Buenas Prácticas de Gestión presentadas por Gerentes Públicos (2018) nos explican que existen siete criterios para definir y evaluar a una Buena Práctica estos son: bienestar ciudadano, replicabilidad, relevancia, iniciativa, creatividad, eficiencia e integralidad. Las buenas prácticas son presentadas por diferentes gerentes públicos de todo el país y son evaluadas por un jurado, siguiendo los criterios señalados, con el objetivo de reconocer a un ganador por cada categoría y a diversas menciones honrosas dentro de las mismas.

Para efectos de la presente investigación nos hemos propuesto realizar un análisis que nos permita identificar la presencia y relevancia del factor político dentro de las ganadoras del Concurso de Buenas Prácticas a cargo de SERVIR. Para esto, hemos tomado las buenas prácticas ganadoras de los años 2013, 2014, 2015 y 2016 (debido a que su contenido se encuentra publicado con detalle en la página web de SERVIR) y hemos identificado la presencia de la coordinación de políticas públicas y del relacionamiento con el entorno político por parte de los mismos directivos públicos. 


\begin{tabular}{|c|c|c|c|}
\hline \multirow[t]{2}{*}{ Año } & \multirow[t]{2}{*}{ Nombre } & \multicolumn{2}{|c|}{ El factor político } \\
\hline & & $\begin{array}{l}\text { Coordinación de } \\
\text { políticas }\end{array}$ & $\begin{array}{l}\text { Relacionamiento con } \\
\text { el entorno }\end{array}$ \\
\hline 2013 & $\begin{array}{l}\text { Licencia social para proyectos con } \\
\text { externalidades negativas }\end{array}$ & & \\
\hline 2013 & $\begin{array}{l}\text { Optimización de los procesos "Pago a } \\
\text { proveedores" y "Pago de viáticos" a } \\
\text { través de la certificación ISO } \\
9001: 2008 \text { " " "Rediseño para la } \\
\text { Simplificación del Proceso de } \\
\text { Asignación Pasajes y Viáticos" }\end{array}$ & & \\
\hline 2013 & $\begin{array}{l}\text { Supervisión del consumo mensual de } \\
\text { energía eléctrica; por facturación } \\
\text { excesiva }\end{array}$ & & \\
\hline 2013 & $\begin{array}{l}\text { Reordenamiento de Archivo Central } \\
\text { de Expedientes Judiciales }\end{array}$ & & \\
\hline 2013 & $\begin{array}{l}\text { Gerentes Públicos construyendo } \\
\text { transparencia y legalidad }\end{array}$ & & \\
\hline 2013 & $\begin{array}{l}\text { Información en línea de pago de } \\
\text { proveedores }\end{array}$ & & \\
\hline 2014 & $\begin{array}{l}\text { Programa de Intervención para } \\
\text { Familias con Adolescentes en } \\
\text { Conflicto con la Ley }\end{array}$ & & \\
\hline
\end{tabular}




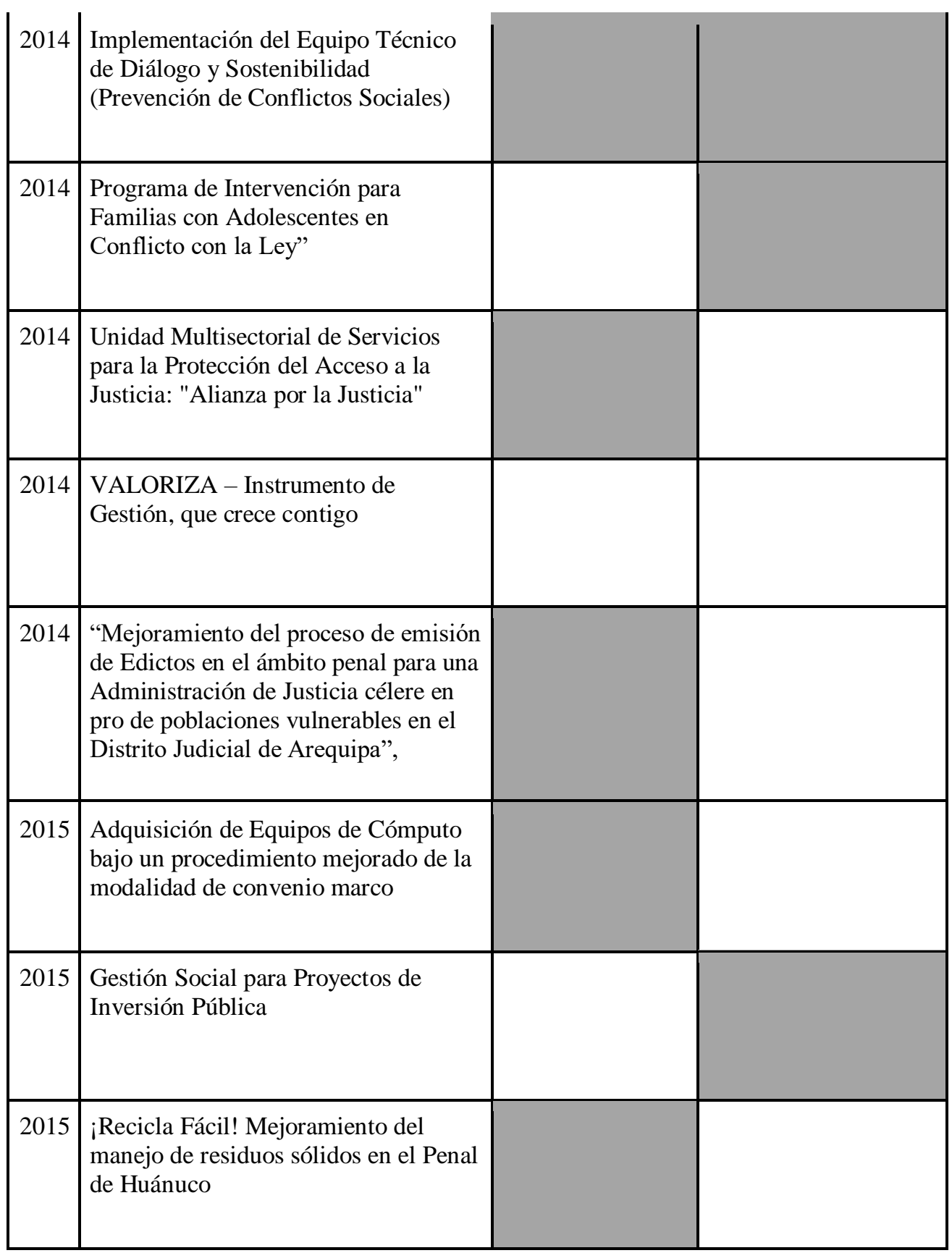




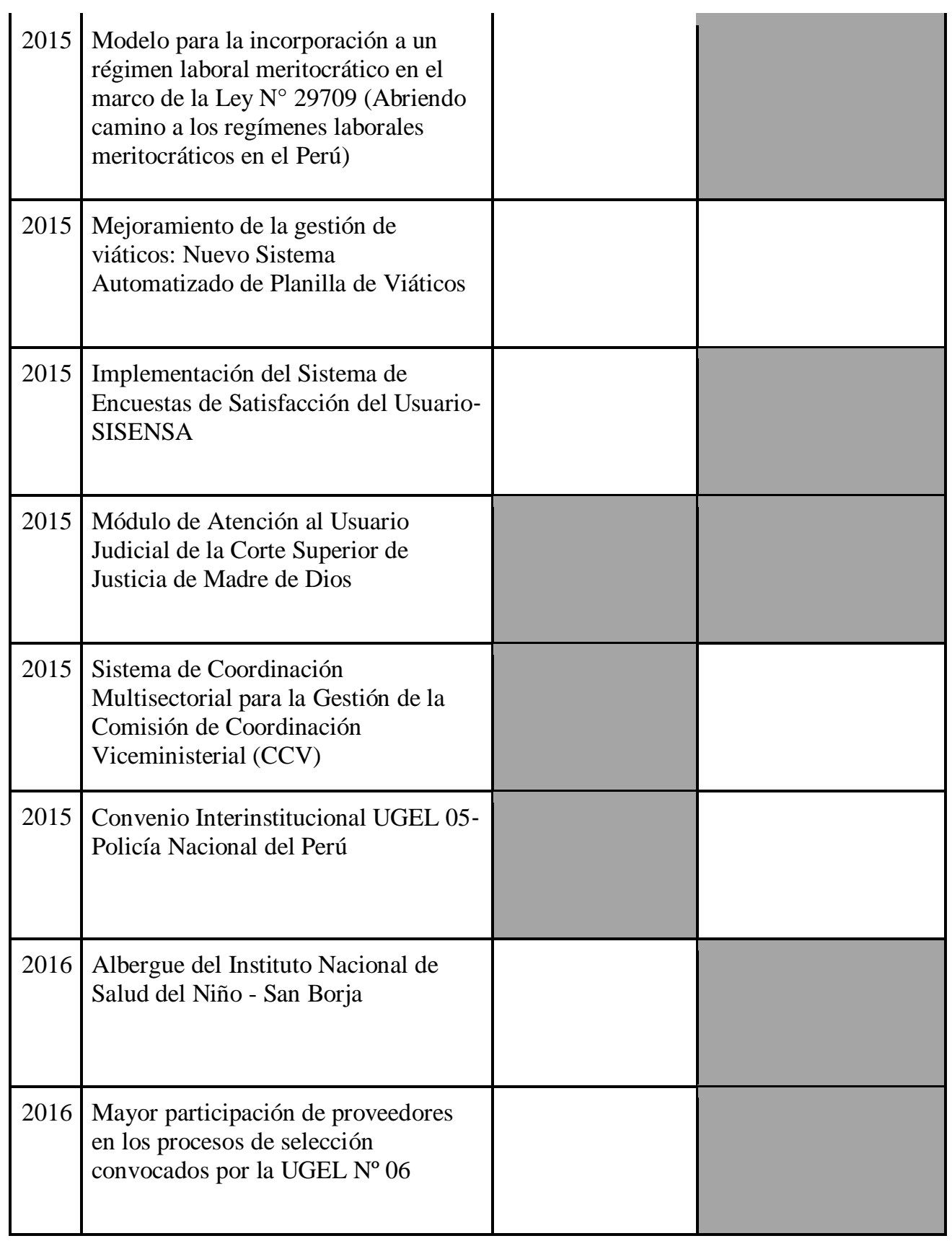




\begin{tabular}{|c|c|c|}
\hline 2016 & $\begin{array}{l}\text { Contratación corporativa - } \\
\text { "Contratación del servicio de } \\
\text { vigilancia para } 67 \text { instituciones } \\
\text { educativas de jornada escolar } \\
\text { completa" }\end{array}$ & \\
\hline 2016 & $\begin{array}{l}\text { Calidad de servicio y atención al } \\
\text { usuario }\end{array}$ & \\
\hline 2016 & $\begin{array}{l}\text { Servicio de orientación y atención, } \\
\text { general y especializada al usuario - } \\
\text { S.O.I. UGEL No } 1\end{array}$ & \\
\hline 2016 & Atención en lenguaje de señas & \\
\hline 2016 & $\begin{array}{l}\text { Red Nacional de Telesalud en Cirugía } \\
\text { Pediátrica y Trasplantes }\end{array}$ & \\
\hline 2016 & $\begin{array}{l}\text { Experiencia de Diplomado de } \\
\text { Atención General }\end{array}$ & \\
\hline 2016 & $\begin{array}{l}\text { Diseño e Implementación de un } \\
\text { Sistema de Monitoreo de Gestión } \\
\text { Educativa Territorial }\end{array}$ & \\
\hline 2016 & $\begin{array}{l}\text { Protección financiera y disponibilidad } \\
\text { de medicamentos como recursos } \\
\text { críticos para la cobertura de servicios } \\
\text { de salud mental en el Instituto } \\
\text { Nacional de Salud Mental "Honorio } \\
\text { Delgado - Hideyo Noguchi" 2013- } \\
2015\end{array}$ & \\
\hline
\end{tabular}




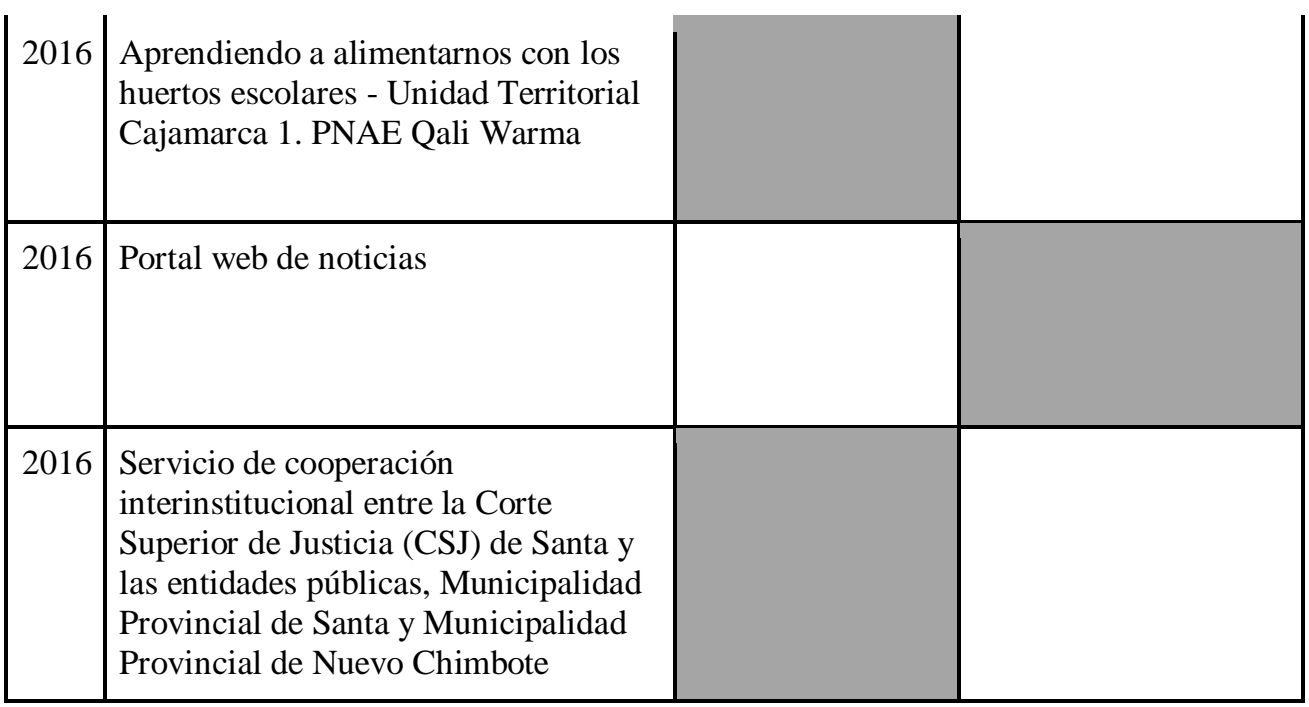

Cuadro 3. La Presencia del Factor Político dentro de las Buenas Prácticas premiadas por SERVIR. Elaboración propia sobre la base de SERVIR 2013, 2014, 2015 y 2016b

\begin{tabular}{|c|c|c|c|c|c|}
\hline Año & $\begin{array}{l}\text { Presencia } \\
\text { de ambos }\end{array}$ & $\begin{array}{l}\text { Presencia solo de } \\
\text { coordinación }\end{array}$ & $\begin{array}{l}\text { Presencia solo de } \\
\text { relacionamiento con } \\
\text { el entorno }\end{array}$ & $\begin{array}{l}\text { Ninguno } \\
\text { está } \\
\text { presente }\end{array}$ & $\begin{array}{l}\text { Tota } \\
\text { de } \\
\text { casos }\end{array}$ \\
\hline 2013 & 0 & 1 & 1 & 4 & 6 \\
\hline 2014 & 1 & 2 & 1 & 2 & 6 \\
\hline 2015 & 1 & 4 & 3 & 1 & 9 \\
\hline 2016 & 1 & 5 & 3 & 4 & 13 \\
\hline Total & 3 & 12 & 8 & 11 & 34 \\
\hline
\end{tabular}

Cuadro 4. Presencia del Factor Político en las buenas practicas premiadas por SERVIR según año. Elaboración propia sobre la base de SERVIR 2013, 2014, 2015 y 2016b 
Según lo observado en los cuadros número 3 y 4, hemos podido constatar que; a partir de 34 casos analizados, 12 de ellos han recurrido solo a la coordinación en políticas públicas, 8 de ellos han recurrido solo al relacionamiento con el entorno político y 3 casos han contado con la presencia de ambas prácticas en su desarrollo. Es decir, 23 casos de un total de 34 han recurrido al menos a alguna de las prácticas que hemos identificado en la presente investigación, como partes del factor político de las políticas públicas. Este factor político ha estado presente en, al menos, el $67.6 \%$ del total de las Buenas Prácticas premiadas por SERVIR durante los años 2013, 2014, 2015 y 2016. También podemos revisar el Anexo $\mathrm{N}^{\circ} 1$ del presente documento, en el cual encontraremos al cuadro $\mathrm{N}^{\circ} 3$ de forma mucho más detallada con el elemento del factor político debidamente identificado en cada caso.

Asimismo, si hacemos un análisis por años, podemos observar en el cuadro $\mathrm{N}^{\circ} 4$ que el año 2015 es cuando ha habido una mayor presencia del factor político dentro de las políticas premiadas, pues solo 1 caso de 9 no ha tenido la presencia de la coordinación de políticas públicas ni de la relación con el entorno político en su desarrollo. Por otro lado, podemos verificar también que el año 2013 es cuando el factor político ha estado menos presente dentro de las buenas prácticas premiadas, ya que 4 de los 6 casos de este año tampoco han presentado ninguno de los elementos constitutivos del factor política, analizados en esta investigación. 


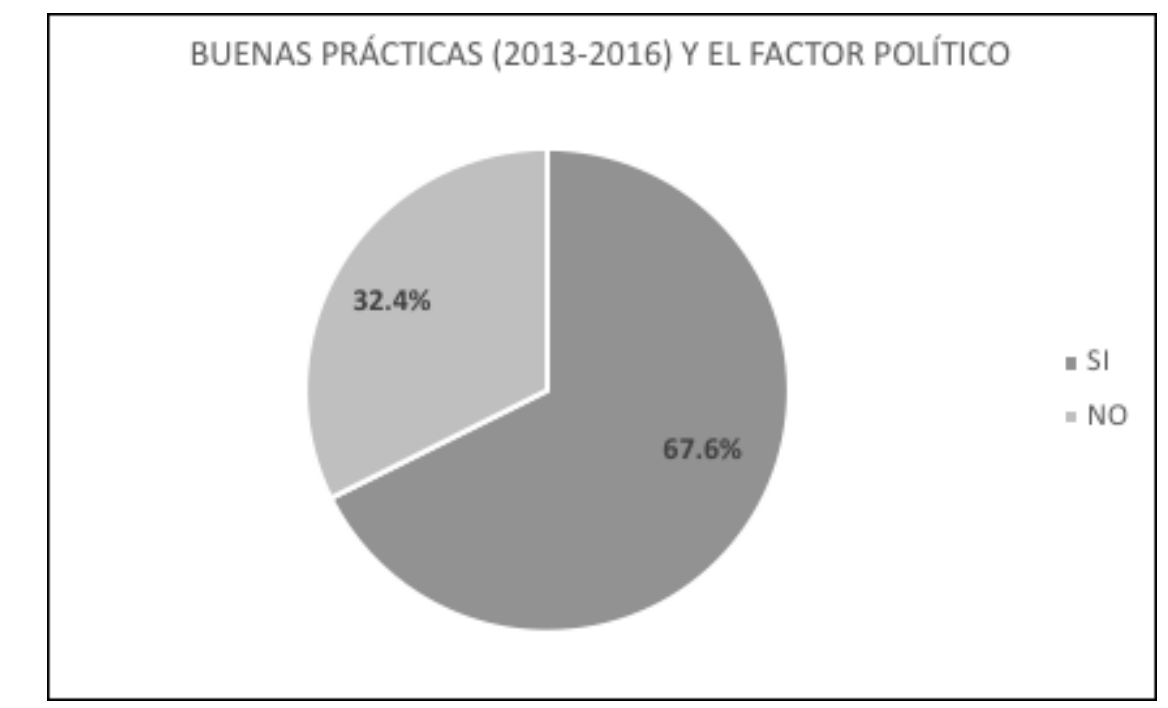

Figura 1. Presencia del Factor Político dentro de las Buenas Prácticas premiadas por SERVIR 2013-2016. Elaboración propia

La tres políticas que han contado con la presencia de ambos recursos, las cuales son la implementación del Equipo Técnico de Diálogo y Sostenibilidad (Prevención de Conflictos Sociales), el módulo de Atención al Usuario Judicial de la Corte Superior de Justicia de Madre de Dios y el diseño e Implementación de un Sistema de Monitoreo de Gestión Educativa Territorial, se han desarrollado en un contexto de gran cantidad de actores involucrados, de dificultades relacionadas a la resistencia al cambio en medio de una gran cantidad de intereses contrapuestos. Las habilidades políticas en los directivos públicos a cargo de estas han sido relevantes para el cumplimiento de los objetivos de estas iniciativas y han permitido, inclusive, que estas sean reconocidas como buenas prácticas premiadas y reconocidas en sus respectivos años.

Por su parte, específicamente en el relacionamiento con el entorno para el correcto desarrollo de las políticas premiadas por SERVIR, se observa que, en la gran mayoría de los casos, la sociedad civil resulta ser un actor crucial para llevar adelante los objetivos de política pública. En primer lugar, en varios de los casos aquí señalados, se muestra que las habilidades del directivo público para conseguir el apoyo de ciertos sectores de la población, los cuales se mostraban reacios a los proyectos en un principio, resultan de 
vital importancia. Así, por ejemplo, en el año 2013, la práctica denominada "Licencia social para proyectos con externalidades negativas", mostró que la sensibilización en la sociedad sobre la necesidad de la construcción de establecimientos penitenciarios resultó clave para el desarrollo exitoso del proyecto. De forma similar, en el año 2015, la práctica denominada "Gestión social para proyectos de inversión pública", sigue el mismo patrón desarrollado en la práctica anterior. En este último caso, la realización de talleres de involucrados, talleres informativos y visitas guiadas, evitaron la paralización de los proyectos de construcción de establecimientos penitenciarios.

En esa línea, otras dos prácticas muestran la necesidad de establecer nexos con la sociedad, sobretodo en aquellos casos en los que la población objetivo de la política posee características particulares que pueden dificultar el cumplimiento de las metas propuestas. Por ejemplo, en el año 2014, la práctica denominada "Programa de Intervención para Familias con Adolescentes en Conflicto con la Ley", muestra que, dada la situación vulnerabilidad en la que se encuentran los menores de edad infractores de la ley, se hizo necesario un trabajo articulado con sus familias para poder asegurar la no reincidencia y el cumplimiento de los objetivos de la medida judicial. En ese sentido, la práctica denominada "Albergue del Instituto Nacional de Salud del Niño - San Borja", ganadora en el año 2016, mostró que existía una deficiencia en la atención a los niños, provenientes de zonas alejadas del país, debido a la imposibilidad de los padres de afrontar los costos que implican permanecer durante todo el proceso de atención de los niños. Así, la construcción de albergues, ayudó a disminuir tales costos y permitió a los padres permanecer al lado de sus hijos, mientras se encontraba siendo atendido.

Respecto a las políticas que no han contado con ninguno de los elementos que hemos propuesto como parte del factor político de las políticas públicas, podemos decir que en su mayoría se han centrado en mejorar y acrecentar la efectividad de sus procesos administrativos. Queda pendiente un análisis de estas buenas prácticas bajo una mirada más amplia que contenga otros elementos adicionales dentro del factor político. 


\section{Conclusiones}

Sobre la base de todo lo expuesto podemos afirmar, en primer lugar, que el factor político dentro de las políticas públicas ocupa un papel relevante, y el caso peruano no es una excepción, más allá de su contexto de despolitización particular. Las Buenas Prácticas premiadas por la Autoridad Nacional del Servicio Civil peruano han reconocido indirectamente a un gran número de iniciativas que han contemplado a la coordinación de políticas públicas y a la relación con el entorno político (67.6\% de todos sus premiados entre el 2013 al 2016). Este hecho refleja que la política dentro de las políticas públicas se encuentra presente dentro de las funciones que los directivos públicos realizan en el día a día, a pesar de encontrarse, por lo general, invisibilizado. Los contextos particulares del desarrollo de las políticas públicas obligan muchas veces a coordinar con otros actores, a estar al pendiente de los entornos políticos actuales y a recurrir la negociación de intereses, es decir a hacer política.

En segundo lugar, podemos confirmar la naturaleza política dentro del rol de los directivos públicos. Si bien es importante la presencia de habilidades técnicas que permitan dar viabilidad y sustento a las iniciativas en políticas públicas, es relevante tener en cuenta también las funciones políticas que se realizan en el día a día. Los directivos públicos también forman parte de la decisión pública y son parte del gobierno de un país, desconocer su labor política es reducir gran parte del análisis sobre la realidad.

Asimismo, afirmamos también, en tercer lugar, la gran relevancia de los múltiples actores en las políticas públicas, dentro y fuera del gobierno. El carácter público de las políticas públicas y el sistema democrático de un gran número de países hace que la decisión pública tome diversos rumbos a los que en un inicio se pudieron haber pensado. El factor político, al cual nos referimos en la presente investigación, también hace referencia a cómo los diversos actores compiten, disputan espacios y debaten sus intereses dentro del desarrollo de las políticas públicas; este proceso es relevante para todo funcionario público.

Finalmente, quisiéramos resaltar la importancia de seguir generando formas de ver el rol político dentro de los gobiernos. Nuestra propuesta es un primer 
acercamiento en la búsqueda de generar mejores políticas públicas para los ciudadanos, mejores gobiernos y -también- reducir el nivel de conflictividad dentro de las decisiones tomadas por los gobernantes y los directivos públicos. 


\section{Bibliografía}

Acevedo, J.L. (2017). En política no hay vacíos. Sistema de medios de comunicación y sus implicancias para la democracia en el Perú. (Tesis de doctorado, Pontifica Universidad Católica del Perú, Facultad de Ciencias Sociales. Lima, Perú).

Silke, A., \& Kriesi, H. (2007). The Network Approach. En P. Sabatier (Ed.), Theories of the Policy Process. Colorado: Westview Press.

Alza, C. (2018). Más allá del escritorio: La articulación de los directivos públicos con el entorno político [Consultoría elaborada para la Autoridad Nacional del Servicio civil - SERVIR]. Lima

Amengual, M. (2016).Politicized Enforcement in Argentina: Labor and Environmental Regulation. New York: Cambridge University Press. https://doi.org/10.1017/CBO9781316476901

Barzelay, M. (2001). The New Public Management. Improving research and policy dialogue. San Francisco: University of California Press.

Cantero, J. (2009). El personal directivo profesional. En F. Castillo, \& J. Quesada (Eds.), Manual de Empleo Público (pp.165-174). Iustel.

Carta Iberoamericana de la Función Pública. (2003). Resolución $N^{o} 11$ de la Declaración de Santa Cruz de la Sierra [Presentación en V Conferencia Iberoamericana de Ministros de Administración Pública y Reforma del Estado]. Bolivia.

Congreso de la República del Perú. (4 de julio de 2013). Ley del Servicio Civil [Ley $\mathrm{N}^{\circ}$ 30057]. Recuperado de https://storage.servir.gob.pe/servicio-civil/Ley\%2030057.pdf

Dye, T. (1972). Understanding Public Policy. New Jersey: Prentice Hall.

Gorriti, M. (2010). Los Directivos Públicos Profesionales (DPP) en la AGE (pp. Faltan laspáginas). Recuperado de https://www.academia.edu/30068177/Los Directivos P\%C3\%BAblic 
os_Profesionales_DPP_en_la_AGE [Consulta: 22 de setiembre de 2018].

Guerrero, O. (2009). El fin de la nueva gestión pública. Revista Chilena de Administración Pública, (13), 5-22.

Gray, B. (1989). Collaborating finding a common ground for multiparty problems. San Francisco: Jossey-Bass Publishers.

Kingdon, J. (2004). Agendas, Alternatives and Public Policies. New York: Longman.

Lemieux, V. (1995). L'étude des politiques publiques. Sainte-Foy: Les Presses de l'Université Laval.

Licha, I., \& G. Molina. (2006). Coordinación de la política social: criterios para avanzar. Washington: INDES.

Longo, F. (1999). Política y gerencia pública en los gobiernos locales, en Gobierno Local y Modelo Gerencial. Barcelona: Fundación Pi y Sunyer.

(2005). La expansión de la dirección pública profesional: apuntes desde la perspectiva española [Presentación de $\mathrm{X}$ Congreso Internacional del CLAD sobre la Reforma del Estado y de la Administración Pública]. Santiago de Chile.

Losada, C. (1999). La función de dirigir en la administración pública. En C. Losada (Ed.), ¿De burócratas a gerentes? Las ciencias de la gestión aplicadas a la administración del Estado. Washington: BID.

Maggiolo, I., \& Perozo, J. (2007). Políticas Públicas: Proceso de concertación Estado-Sociedad. Revista venezolana de gerencia (RVG), 12(39), 272-292.

Martínez Nogueira, R. (2010). La coherencia y coordinación en las políticas públicas. Aspectos conceptuales y experiencias. En C. Acuña, R. Martínez Nogueira, \& F. Repetto (Eds.), Los desafíos de la coordinación y la integralidad de las políticas y la gestión Pública. 
Buenos Aires: Programa de Modernización del Estado. Jefatura de Gabinete de Ministros.

Mejía. J. (2004). El directivo público: entre la política y la técnica de dirección [Presentación en XIX Congreso Internacional del CLAD sobre Reforma del Estado y de la Administración Pública]. Quito.

Moore, M.H. (1998). Gestión estratégica y creación de valor en el sector público. Barcelona: Paidos.

Navarro, A. (2013). La coordinación intergubernamental en las políticas de superación de pobreza en México. El caso del programa Hábitat. México D.F: Centro de Estudios Sociales y de Opinión Pública.

Navarro, C. (2008). El estudio de las Políticas Públicas. Revista Jurídica de la Universidad Autónoma de Madrid, (17), 231-255.

Peters, G. (1998). Managing Horizontal Government. The Politics of Coordination. Research paper No 21. Canadá: Canadian Centre for Management Development.

Pollit, C., \& Bouckaert, G. (2000). Public Management Reform. A comparative analysis. Oxford: Oxford University Press.

Ramió, C. (2001). Los problemas de la implantación de la nueva gestión pública en las administraciones públicas latinas. Revista del CLAD Reforma y Democracia, (21),1-28.

(2014). Management avanzado (pero fácil y breve) para directivos públicos. Recuperado de http://www.gigapp.org/ewp/index.php/GIGAPP-EWP/article/view/57 [Consulta: 22 de setiembre del 2018].

Repetto, F., \& Fernández, J.P. (2012). Coordinación de políticas, programas y proyectos sociales. Buenos Aires: Fundación CIPPEC.

Rogers, R., \& Nelson, G. (2015). El directivo público hoy: contextos, roles y desafíos. Santiago de Chile: Publicación del Servicio Civil. 
SERVIR. (2013). Ganadores del Concurso de Buenas Prácticas de Gestión de los Gerentes Públicos - SERVIR 2013. Recuperado de https://www.servir.gob.pe/gerencia-publica/gerentespublicos/ganadores-del-concurso-buenas-practicas-2013/ [Consulta: 3 de octubre del 2018].

(2014). Ganadores del Concurso de Buenas Prácticas de Gestión de los Gerentes Públicos - SERVIR 2014. Recuperado de http://files.servir.gob.pe/WWW/files/Gerentes-Publicos/GanadoresConcurso-2014.pdf

[Consulta: 3 de octubre del 2018].

(2015). Ganadores del Concurso de Buenas Prácticas de Gestión de los Gerentes Públicos - SERVIR 2015. Recuperado de https://storage.servir.gob.pe/gerentespublicoscbp/2015/BuenasPractic as 2015 Ganadores.pdf [Consulta: 3 de octubre del 2018]

(2016a) Modelo de gestión del grupo de directivos públicos del servicio civil peruano. Recuperado de https://storage.servir.gob.pe/publicacionessc/2016/Modelo de Gestion Directivos Publicos Ago16.pdf [Consulta: 3 de octubre del 2018]

(2016b). Ganadores del Concurso de Buenas Prácticas de Gestión de los Gerentes Públicos - SERVIR 2016. Recuperado de https://storage.servir.gob.pe/gerentespublicoscbp/2016/BuenasPractic as_2016_Ganadores.pdf [Consulta: 3 de octubre del 2018].

(2018). Bases del Concurso 2018 "Buenas prácticas de gestión presentadas por gerentes públicos”. Recuperado de https://storage.servir.gob.pe/gerentes-publicos-cbp/2018/Bases-

Concurso-Buenas-Practicas-Gestion-2018.pdf [Consulta: 3 de octubre del 2018]

Stein, E., \& Tomassi, M. (2006). La política de las políticas públicas. Revista Política y Gobierno, 13(2) 407. 
Subirats, J., Knoepfel, P., Larrue, C., \& F.Varone. (2008). Análisis y Diseño de Políticas Públicas. Barcelona: Editorial Ariel.

Villoria, M. (2009). La función directiva profesional. En La dirección pública profesional en España. Madrid: Marcial Pons, Ediciones Jurídicas y Sociales. 


\begin{abstract}
ANEXO
Cuadro detallado de la práctica identificada como parte del factor político dentro de las Buenas Prácticas premiadas por servir entre los años 2013 y 2016
\end{abstract}

\begin{tabular}{|c|c|c|c|}
\hline \multirow[t]{2}{*}{ Año } & \multirow[t]{2}{*}{ Nombre } & \multicolumn{2}{|c|}{ El factor político } \\
\hline & & $\begin{array}{c}\text { Coordinación de } \\
\text { políticas }\end{array}$ & $\begin{array}{c}\text { Relacionamiento con el } \\
\text { entorno }\end{array}$ \\
\hline 2013 & $\begin{array}{l}\text { Licencia social para } \\
\text { proyectos con externalidades } \\
\text { negativas }\end{array}$ & & $\begin{array}{l}\text { Desarrollo de un modelo } \\
\text { exitoso de incidencia en la } \\
\text { sociedad civil que permita } \\
\text { su sensibilización sobre la } \\
\text { construcción de } \\
\text { Establecimientos } \\
\text { Penitenciarios }\end{array}$ \\
\hline 2013 & $\begin{array}{l}\text { Optimización de los } \\
\text { procesos "Pago a } \\
\text { proveedores" y "Pago de } \\
\text { viáticos" a través de la } \\
\text { certificación ISO } \\
9001: 2008 \text { " " "Rediseño } \\
\text { para la Simplificación del } \\
\text { Proceso de Asignación } \\
\text { Pasajes y Viáticos" }\end{array}$ & & \\
\hline 2013 & $\begin{array}{l}\text { Supervisión del consumo } \\
\text { mensual de energía eléctrica; } \\
\text { por facturación excesiva }\end{array}$ & & \\
\hline 2013 & $\begin{array}{l}\text { Reordenamiento de Archivo } \\
\text { Central de Expedientes }\end{array}$ & & \\
\hline
\end{tabular}




\begin{tabular}{|c|c|c|c|}
\hline & Judiciales & & \\
\hline 2013 & $\begin{array}{l}\text { Gerentes Públicos } \\
\text { construyendo transparencia y } \\
\text { legalidad }\end{array}$ & $\begin{array}{l}\text { Construcción de un } \\
\text { sistema de transparencia } \\
\text { en la contratación de } \\
\text { proveedores entre dos } \\
\text { jefaturas zonales del } \\
\text { programa PRONAA } \\
\text { (Chimbote y Trujillo) } \\
\text { además de la articulación } \\
\text { con funcionarios locales } \\
\text { de ambas ciudades. }\end{array}$ & \\
\hline 2013 & $\begin{array}{l}\text { Información en línea de pago } \\
\text { de proveedores }\end{array}$ & & \\
\hline 2014 & $\begin{array}{l}\text { Programa de Intervención } \\
\text { para Familias con } \\
\text { Adolescentes en Conflicto } \\
\text { con la Ley }\end{array}$ & & \\
\hline 2014 & $\begin{array}{l}\text { Implementación del Equipo } \\
\text { Técnico de Diálogo y } \\
\text { Sostenibilidad (Prevención } \\
\text { de Conflictos Sociales) }\end{array}$ & $\begin{array}{l}\text { Creación de la Unidad de } \\
\text { Conflictos Sociales y } \\
\text { prevención de crisis, que } \\
\text { permita introducir } \\
\text { mecanismos de } \\
\text { coordinación } \\
\text { interinstitucional dentro } \\
\text { de la región para generar } \\
\text { acciones frente a los } \\
\text { conflictos sociales. }\end{array}$ & $\begin{array}{l}\text { Generación de } \\
\text { conocimientos sobre el } \\
\text { estado, cantidad y } \\
\text { magnitud de los conflictos } \\
\text { sociales en a región San } \\
\text { Martín. }\end{array}$ \\
\hline
\end{tabular}




\begin{tabular}{|c|c|c|c|}
\hline 2014 & $\begin{array}{l}\text { Programa de Intervención } \\
\text { para Familias con } \\
\text { Adolescentes en Conflicto } \\
\text { con la Ley }\end{array}$ & & $\begin{array}{l}\text { Mapeo y trabajo con } \\
\text { familias de adolescentes } \\
\text { infractores de la ley. } \\
\text { Generación de estrategias } \\
\text { para el establecimiento de } \\
\text { vínculos con ellos. }\end{array}$ \\
\hline 2014 & $\begin{array}{l}\text { Unidad Multisectorial de } \\
\text { Servicios para la Protección } \\
\text { del Acceso a la Justicia: } \\
\text { "Alianza por la Justicia" }\end{array}$ & $\begin{array}{l}\text { Creación de una unidad } \\
\text { con la participación del } \\
\text { Ministerio de la Mujer y } \\
\text { Poblaciones Vulnerables, } \\
\text { Ministerio de Justicia y el } \\
\text { Colegio de Abogados del } \\
\text { Callao. }\end{array}$ & \\
\hline 2014 & $\begin{array}{l}\text { VALORIZA - Instrumento } \\
\text { de Gestión, que crece } \\
\text { contigo }\end{array}$ & & \\
\hline 2014 & $\begin{array}{l}\text { "Mejoramiento del proceso } \\
\text { de emisión de Edictos en el } \\
\text { ámbito penal para una } \\
\text { Administración de Justicia } \\
\text { célere en pro de poblaciones } \\
\text { vulnerables en el Distrito } \\
\text { Judicial de Arequipa", }\end{array}$ & $\begin{array}{l}\text { Creación de un aplicativo } \\
\text { web, involucrando la } \\
\text { participación de los } \\
\text { órganos jurisdiccionales } \\
\text { de las provincias de } \\
\text { Arequipa, Camaná e } \\
\text { Islay. }\end{array}$ & \\
\hline 2015 & $\begin{array}{l}\text { Adquisición de Equipos de } \\
\text { Cómputo bajo un } \\
\text { procedimiento mejorado de } \\
\text { la modalidad de convenio } \\
\text { marco }\end{array}$ & $\begin{array}{l}\text { Creación de un trabajo en } \\
\text { conjunto con la OSCE } \\
\text { para la aplicación del } \\
\text { convenio marco. } \\
\text { Modalidad especial para } \\
\text { ejecutar una compra }\end{array}$ & \\
\hline
\end{tabular}




\begin{tabular}{|c|c|c|c|}
\hline 2015 & $\begin{array}{l}\text { Gestión Social para } \\
\text { Proyectos de Inversión } \\
\text { Pública }\end{array}$ & & $\begin{array}{l}\text { Gestión social, mediante } \\
\text { comunicación efectiva y } \\
\text { talleres con la sociedad } \\
\text { para la construcción de } \\
\text { unidades de albergue en el } \\
\text { sistema penitenciario }\end{array}$ \\
\hline 2015 & $\begin{array}{l}\text { ¡Recicla Fácil! } \\
\text { Mejoramiento del manejo de } \\
\text { residuos sólidos en el Penal } \\
\text { de Huánuco }\end{array}$ & $\begin{array}{l}\text { Generación de un } \\
\text { programa de tratamiento } \\
\text { de residuos sólidos } \\
\text { gracias a la coordinación } \\
\text { efectiva del personal del } \\
\text { INPE, Poder Judicial y de } \\
\text { la PNP. }\end{array}$ & \\
\hline 2015 & $\begin{array}{l}\text { Modelo para la } \\
\text { incorporación a un régimen } \\
\text { laboral meritocrático en el } \\
\text { marco de la Ley No } 29709 \\
\text { (Abriendo camino a los } \\
\text { regímenes laborales } \\
\text { meritocráticos en el Perú) }\end{array}$ & & $\begin{array}{l}\text { Generación de estrategias } \\
\text { para enfrentar una } \\
\text { situación de resistencia, } \\
\text { por parte de los } \\
\text { trabajadores del INPE, } \\
\text { para el paso de estos a un } \\
\text { nuevo régimen laboral }\end{array}$ \\
\hline 2015 & $\begin{array}{l}\text { Mejoramiento de la gestión } \\
\text { de viáticos: Nuevo Sistema } \\
\text { Automatizado de Planilla de } \\
\text { Viáticos }\end{array}$ & & \\
\hline 2015 & $\begin{array}{l}\text { Implementación del Sistema } \\
\text { de Encuestas de Satisfacción } \\
\text { del Usuario- SISENSA }\end{array}$ & & $\begin{array}{l}\text { Interacción con los } \\
\text { usuarios del servicio para } \\
\text { conocer sus percepciones } \\
\text { en la atención de la Corte } \\
\text { Superior de Justicia de } \\
\text { Arequipa. Generación de } \\
\text { vínculos con una } \\
\text { población insatisfecha con }\end{array}$ \\
\hline
\end{tabular}




\begin{tabular}{|l|l|l|l|} 
& & \\
2015 & $\begin{array}{l}\text { Módulo de Atención al } \\
\text { Usuario Judicial de la Corte } \\
\text { Superior de Justicia de } \\
\text { Madre de Dios }\end{array}$ & $\begin{array}{l}\text { Implementación de una } \\
\text { ventanilla única en } \\
\text { coordinación con el } \\
\text { Ministerio Público y los } \\
\text { defensores de oficio, por } \\
\text { parte de la Corte Superior } \\
\text { de Justicia de Madre de } \\
\text { Dios }\end{array}$ & $\begin{array}{l}\text { Mejora en la cercanía al } \\
\text { usuario para facilitar el } \\
\text { desarrollo de sus trámites }\end{array}$ \\
\hline 2015 & $\begin{array}{l}\text { Sistema de Coordinación } \\
\text { Multisectorial para la } \\
\text { Gestión de la Comisión de } \\
\text { Coordinación } \\
\text { Viceministerial (CCV) }\end{array}$ & $\begin{array}{l}\text { Creación de comisiones } \\
\text { de coordinación } \\
\text { viceministerial que } \\
\text { permitan mejorar el } \\
\text { proceso de coordinación } \\
\text { interinstitucional entre los } \\
\text { ministerios del ejecutivo. }\end{array}$ & \\
\hline 2015 & $\begin{array}{l}\text { Convenio Interinstitucional } \\
\text { UGEL 05- Policia Nacional } \\
\text { del Perú }\end{array}$ & $\begin{array}{l}\text { Trabajo interinstitucional } \\
\text { entre la UGEL 05 y la } \\
\text { PNP dentro de las } \\
\text { instalaciones del ex IIEE } \\
\text { César Vallejo No1180 }\end{array}$ & \\
\hline & & \\
\hline
\end{tabular}




\begin{tabular}{|c|c|c|c|}
\hline 2016 & $\begin{array}{l}\text { Albergue del Instituto } \\
\text { Nacional de Salud del Niño - } \\
\text { San Borja }\end{array}$ & & $\begin{array}{l}\text { Generación de un } \\
\text { albergue para los padres } \\
\text { de familia de los } \\
\text { pacientes, provenientes de } \\
\text { ciudades fuera de Lima, } \\
\text { del Instituto Nacional de } \\
\text { Salud del Niño. Esto } \\
\text { luego de observar las } \\
\text { dificultades de las } \\
\text { familias de los pacientes, } \\
\text { todos ellos menores de } \\
\text { edad }\end{array}$ \\
\hline 2016 & $\begin{array}{l}\text { Mayor participación de } \\
\text { proveedores en los procesos } \\
\text { de selección convocados por } \\
\text { la UGEL N } 06\end{array}$ & & $\begin{array}{l}\text { Identificación y mapeo de } \\
\text { las dificultades, de } \\
\text { empresas privadas, para } \\
\text { presentarse a ser } \\
\text { proveedores en la UGEL } \\
\text { No6. La superación de } \\
\text { estas permitió un ahorro } \\
\text { de más de } 879 \text { mil nuevos } \\
\text { soles. }\end{array}$ \\
\hline 2016 & $\begin{array}{l}\text { Contratación corporativa - } \\
\text { "Contratación del servicio de } \\
\text { vigilancia para } 67 \\
\text { instituciones educativas de } \\
\text { jornada escolar completa" }\end{array}$ & $\begin{array}{l}\text { Generación de un } \\
\text { convenio entre las } 7 \\
\text { UGEL que conforman } \\
\text { Lima Metropolitana y la } \\
\text { Dirección Regional de } \\
\text { Lima Metropolitana }\end{array}$ & \\
\hline 2016 & $\begin{array}{l}\text { Calidad de servicio y } \\
\text { atención al usuario }\end{array}$ & & \\
\hline 2016 & $\begin{array}{l}\text { Servicio de orientación y } \\
\text { atención, general y } \\
\text { especializada al usuario - }\end{array}$ & & \\
\hline
\end{tabular}




\begin{tabular}{|c|c|c|c|}
\hline & S.O.I. UGEL $\mathrm{N}^{\circ} 1$ & & \\
\hline 2016 & $\begin{array}{l}\text { Atención en lenguaje de } \\
\text { señas }\end{array}$ & & \\
\hline 2016 & $\begin{array}{l}\text { Red Nacional de Telesalud } \\
\text { en Cirugía Pediátrica y } \\
\text { Trasplantes }\end{array}$ & $\begin{array}{l}\text { Creación de una red } \\
\text { nacional gracias a la } \\
\text { coordinación del Instituto } \\
\text { Nacional de Salud del } \\
\text { Niño en San Borja y } \\
\text { diversos centros } \\
\text { hospitalarios al interior } \\
\text { del país. Se llegó a } 10 \\
\text { instituciones al interior } \\
\text { del país }\end{array}$ & \\
\hline 2016 & $\begin{array}{l}\text { Experiencia de Diplomado } \\
\text { de Atención General }\end{array}$ & & \\
\hline 2016 & $\begin{array}{l}\text { Diseño e Implementación de } \\
\text { un Sistema de Monitoreo de } \\
\text { Gestión Educativa Territorial }\end{array}$ & $\begin{array}{l}\text { Generación de vínculos } \\
\text { entre coordinación entre } \\
\text { la Dirección Regional, las } \\
\text { UGEL de Lima } \\
\text { Metropolitana y el } \\
\text { Ministerio de Economía y } \\
\text { Finanzas }\end{array}$ & $\begin{array}{l}\text { Generación de } \\
\text { presentaciones en } \\
\text { universidades, con la } \\
\text { finalidad de mostrar las } \\
\text { posibles ventajas de la } \\
\text { implementación de la } \\
\text { aplicación. Búsqueda de } \\
\text { apoyo político por parte } \\
\text { de la academia }\end{array}$ \\
\hline
\end{tabular}




\begin{tabular}{|c|c|c|c|}
\hline 2016 & $\begin{array}{l}\text { Protección financiera y } \\
\text { disponibilidad de } \\
\text { medicamentos como } \\
\text { recursos críticos para la } \\
\text { cobertura de servicios de } \\
\text { salud mental en el Instituto } \\
\text { Nacional de Salud Mental } \\
\text { "Honorio Delgado - Hideyo } \\
\text { Noguchi" 2013-2015 }\end{array}$ & $\begin{array}{l}\text { Generación de un espacio } \\
\text { de supervisión y } \\
\text { colaboración entre el } \\
\text { presente Instituto } \\
\text { Nacional de Salud mental } \\
\text { con el SIS y SuSalud }\end{array}$ & \\
\hline 2016 & $\begin{array}{l}\text { Aprendiendo a alimentarnos } \\
\text { con los huertos escolares - } \\
\text { Unidad Territorial } \\
\text { Cajamarca 1. PNAE Qali } \\
\text { Warma }\end{array}$ & $\begin{array}{l}\text { Generación de espacios } \\
\text { de coordinación entre los } \\
\text { Monitores de Gestión } \\
\text { Local del programa Qali } \\
\text { Warma, el sector } \\
\text { agricultura de la región y } \\
\text { las escuelas. }\end{array}$ & \\
\hline 2016 & Portal web de noticias & & $\begin{array}{l}\text { Implementación de un } \\
\text { espacio de mejora en la } \\
\text { relación con los medios } \\
\text { de comunicación respecto } \\
\text { al rol que desempeñan los } \\
\text { fiscales. }\end{array}$ \\
\hline 2016 & $\begin{array}{l}\text { Servicio de cooperación } \\
\text { interinstitucional entre la } \\
\text { Corte Superior de Justicia } \\
\text { (CSJ) de Santa y las } \\
\text { entidades públicas, } \\
\text { Municipalidad Provincial de } \\
\text { Santa y Municipalidad } \\
\text { Provincial de Nuevo } \\
\text { Chimbote }\end{array}$ & $\begin{array}{l}\text { Creación de un espacio de } \\
\text { coordinación y } \\
\text { cooperación entre la } \\
\text { Corte Superior de Justicia } \\
\text { de Santa, la } \\
\text { Municipalidad provincial } \\
\text { de Santa y la } \\
\text { Municipalidad distrital de } \\
\text { Nuevo Chimbote }\end{array}$ & \\
\hline
\end{tabular}

Elaboración propia sobre la base de SERVIR 2013, 2014, 2015 y 2016 b. 